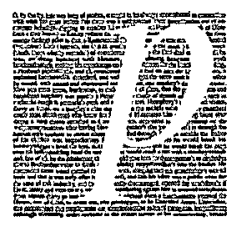

\title{
Hacia una concepción del aforismo como un nuevo discurso crítico
}

\author{
Irma Munguía Zatarain, Gilda Rocha Romero \\ Universidad Autónoma Metropolitana- Iztapalapa, \\ Universidad Pedagógica Nacional
}

\begin{abstract}
T a palabra aforismo alude, etimológicamente, a la actividad de definir. Es un término de origen griego usado desde siglos antes de nuestra era. Hipócrates, en el $\mathrm{S}$. V a de C. estructuró sus preceptos médicos en forma de aforismos, es decir, en pequeñas proposiciones cuya memorización era fácil. Parménides, Heráclito, Pitágoras, entre otros griegos de la antigüedad, emplearon el aforismo para expresar sus ideas sobre filosofia, arte, moral. También encontramos este tipo de composición en las antiguas culturas orientales: el Zend Avesta de Zaratustra o Zoroastro, El libro de los proverbios de Salomón, las enseñanzas de Confucio, Lao Tsé, Mahoma, etc. Muchos pensadores, en distintas épocas y lugares, y sobre diversos asuntos lo han empleado: en la antigua Roma, podemos citar a Séneca, Cicerón, Epicteto; posteriormente, en Inglaterra tenemos a $F$. Bacon y a W. Blake; en Francia, $M$. de Montaigne, Jean de la Bruyère; en Alemania, G. W. Leibniz, G. Lichtenberg, F. Nietzsche, L. Wittgenstein; en España, José Bergamín, R. Gómez de la Serna; en Rumania, E. M. Ciorán, sólo por citar algunos de los que eligieron la escritura aforistica como una forma particular de presentar su pensamiento o buena parte de éste.
\end{abstract}

Poligrafias IV (2003) 231-241

(C) Poligrafias. Revista de Literatura Comparada. División de Estudios de Posgrado, Facultad de

Filosofia y Letras, Universidad Nacional Autónoma de México, Ciudad Universitaria, México 04510 DF.

Tel. (525) $6221835(6)$. Fax (525) $6221801 ; 6160047 ; 6221826$. 
Podemos decir que en cierta tradición crítica, el aforismo se concibe como una frase breve que tiene un propósito doctrinal o didáctico. Por su carácter sintético y sucinto es posible relacionarlo con algunas formas poéticas como el haikú y la tanka, así como con el cliché, el refrán, la sentencia, el proverbio, las máximas.

El haikú y la tanka son formas poéticas con una métrica rígida y, obviamente, son producto de una intención estética (El haikú...1966,11). El cliché es una frase hecha, estereotipada, que una comunidad repite a manera de muletilla; su sentido está altamente codificado y su interpretación depende de la cultura a la que pertenece; algunos ejemplos, correspondientes a la cultura en México, serían: Rojo como una amapola, Hay que echarle ganas. El refrán es una composición pequeña, con cierto ritmo y suele formar parte de la cultura de un pueblo; expresa valores, actitudes y principios tradicionales sobre los que no suele dudarse; por ello, puede decirse que los refranes constituyen parte de la llamada sabiduría popular, por ejemplo: A quien madruga, Dios le ayuda; En el pais de los ciegos, el tuerto es rey. Tanto el cliché como el refrán han sido por lo general, en su origen, formas novedosas o ingeniosas, pero su significado se ha gastado debido al uso. (Riffaterre 1976 y Carreter 1981, 219-232).

La sentencia y el proverbio son expresiones que encierran una supuesta verdad y la comunican de una manera sobria, solemne, docta y categórica (Reyes 1976); la verdad que expresan es producto de la experiencia, del conocimiento $y$, en ese sentido, es un saber estrechamente vinculado con la historia y con la cultura; en ambas composiciones no intervienen los elementos lúdico, irónico y paródico que van a acompañar al aforismo, como veremos más adelante; por ejemplo La ley es dura, pero es la ley; Mejor es el pobre que anda en integridad que el rico de perversos caminos.

La máxima expresa un precepto de carácter moral, un consejo o una enseñanza. Su intención didáctica es notable; por ejemplo, una máxima de conducta podría ser Obrar siempre con honradez; en una empresa Hay que sonreirle siempre al cliente. (Cheymol 1987, 9-25).

Además de estas formas, existen otras expresiones también breves conocidas como pensamientos, citas, frases célebres, apotegmas, adagios, dichos, etcétera (Bartolomé y Vidal 2000, 9-16). Todas ellas tienen una actitud didáctica o enuncian una verdad socialmente aceptada, institucionalizada.

El discurso aforístico al que hacemos referencia en este trabajo se presenta en un tipo de texto que hemos identificado en tratados de filosofía, en libros de aforismos-por supuesto-y en ensayos, relatos, poesía, etc. El discurso de estos textos, lógicamente, está organizado a partir de sus propios fines; sin embargo, en ocasiones es posible destacar frases acabadas, con cierta autonomía, que pretenden encerrar una conclusión o una reflexión, en las cuales se transparenta una verdad que trataremos de caracterizar más adelante. Estas frases pueden tener una lectura independiente de su contexto original $y$, en ese sentido integrarse-desde el punto de vista de la forma y de su significado-a lo que llamaremos aquí expresión aforística. El corpus que utilizamos está conformado por aproximadamente dos mil aforismos, de un promedio de quinientos autores de diferentes culturas y épocas (Munguía y Rocha 1992). 
En la sociedad, existen y siempre han existido prejuicios, ideas, formas de ver, esquemas y certezas, valorados e institucionalizados; sin esos apoyos, la gente dificilmente puede vivir porque es el conjunto de creencias que organiza la vida en sociedad y la determina, casi la conforma. El a forismo, en el sentido en que lo estamos trabajando aquí, es un tipo de discurso que pudiéramos calificar como intrigante, como provocador, puesto que pretende introducir la duda, resquebrajar lo firme y dar un valor a lo incierto, a lo otro, a lo que se nos ha ocultado; para hacerlo, da la impresión de formular una gran verdad-aunque todos sabemos que no necesariamente lo es-para cuestionar y poner en tela de juicio esas certezas e ideas preconcebidas y, con ello, provocar la incertidumbre.

La concepción que presentaremos aquí sobre el aforismo no tiene una intención didáctica ni la de expresar una verdad científica o convencional, como sí lo hacen los refranes, las máximas, los proverbios. Por supuesto, el aforismo tampoco puede identificarse con el discurso literario, aunque en muchas ocasiones emplea recursos o procedimientos muy comunes en los textos literarios; sin duda, habría que decir que el aforismo es un tipo de discurso que tiene características que comparte con otros géneros discursivos pero es posible hablar de ciertas propiedades específicas y particulares del discurso aforístico. Cabe señalar que en este trabajo no nos detendremos en la dimensión estética que pudiera involucrar el aforismo, ni en una discusión mayor sobre las formas genéricas con las que guarda cierto parentesco.

En esta presentación, nos proponemos demostrar que el aforismo es un tipo de discurso que se organiza, fundamentalmente, a partir de la ironía y la parodia; ambas formas coinciden en cuanto a que hacen confluir puntos de vista distintos y en conflicto, lo cual genera desconcierto o un efecto burlesco o lúdico sobre algo: la ironía lo hace expresando seriamente un contenido burlesco y, la segunda lo logra utilizando un discurso construido a partir de otro ya existente, con intención de someterlo a crítica, para descalificarlo, enaltecerlo, ridiculizarlo, etcétera. Pero no sólo quisiéramos referirnos al aforismo como un discurso cuyo propósito central sea el hacer mofa, sino que pensamos que se caracteriza, además, por constituirse en una propuesta de una verdad que pareciera irrebatible, distinta de la que sustenta la lógica y el sentido común. El aforismo permite descubrir lo que está encubierto por la herencia cultural; se trata de verdades que tienen valor no porque sean verificables mediante procedimientos lógicos, sino que su valor radica en que dicen algo nuevo e inesperado, obligan al lector a reflexionar sobre otra dimensión de la realidad, provocan significaciones novedosas, aún no conocidas, y por ello parecen en ocasiones grandes absurdos o grandes verdades.

Enseguida haremos un breve examen de los dos ejes estructuradores del aforismo: la ironía y la parodia (Hutcheon 1992). La primera es un tropo que se caracteriza por decir lo contrario de lo que se cree y de lo que realmente es. Desde este punto de vista, la ironía se relaciona con la antífrasis ya que es producto de una inversión semántica, de una oposición, con frecuencia contrastante entre lo que se enuncia y lo que se quiere hacer entender. La finalidad del empleo irónico de la lengua es burlarse de algo o de alguien y en ese proceso se aproxima a lo cómico, al sarcasmo. 
Marina Mizzau (1984) distingue los aspectos semánticos y pragmáticos en el funcionamiento del discurso irónico. Desde una perspectiva pragmática, la ironía constituye una estrategia de evaluación al destacar los juicios negativos, la reprobación y la censura burlona que subyacen en expresiones serias o elogiosas. En este sentido, asocia la ironía con el humor, la paradoja, los sobreentendidos. Sperber y Wilson (1978) consideran los diversos tipos de ironía como el eco de un enunciado o de un pensamiento, con el fin de poner en evidencia su error, su carácter inadmisible e inoportuno. Sobre el efecto irónico, Carlos Gurméndez $(1990,12)$ ha dicho que la ironía es "esa burla fina y disimulada que puede elevarse a consideraciones negativas sobre el mundo en general y sobre esta sociedad en particular, porque es el veneno del yo." Wayne Booth $(1986,13)$, por su parte, ha señalado que la ironía "socava claridades, abre vistas en las que reina el caós y, o bien libera mediante la destrucción de todo dogma o destruye por el procedimiento de hacer patente el ineludible cáncer de la negación que subyace en el fondo de toda afirmación." Veamos cómo se da el juego irónico en el siguiente aforismo:

(1) En la vaguedad del desierto, la tumba es un oasis, un lugar concreto y un apoyo.

Se cava la tumba para tener un punto fijo en el espacio. Y se muere para no extraviarse. (E.M. Ciorán)

Aquí la inversión se da al asociar tumba con oasis, pues la tumba alude a muerte, a acabamiento, mientras que un oasis-en un desierto-designa o representa la presencia de agua, de salvación, de vida. La ironía se enfatiza al relacionar la tumba con un punto fijo en el espacio, puesto que sabemos que el ser humano siempre necesita y busca un punto fijo, un lugar seguro en el espacio, en donde arraigarse y en donde vivir, pero no en donde morir; el desarrollo irónico se acentúa con la frase conclusiva del final, puesto que relaciona la muerte con el no extravío; se presenta la idea de la muerte como meta del encuentro del ser humano consigo mismo; sin embargo, la idea del encuentro con uno mismo, en nuestra cultura, se concibe como fundamental para la vida.

Veamos otro aforismo:

(2) Si la sentencia contra la mediocridad fuera la pena de muerte, a cada grupo de ejecutados tendria que sumarse un suicidio. (L. Rosenberg)

La argumentación de este aforismo es por sí misma irónica, pues expresa un punto de vista sobre la mediocridad, que nos incluye probablemente a todos y, con ello, se produce la inversión semántica de la que hablamos anteriormente, es decir, no se ve la mediocridad como la concibe la mayoría de la gente; al ser humano le cuesta aceptar su propia mediocridad, se niega a aceptar que sea algo suyo, aunque inconscientemente sabe que es mediocre o que puede serlo ante los ojos de los demás, entonces tiende a juzgar como grises, conformistas, pusilánimes y sin imaginación a los demás y hasta los desprecia por su supuesta y obvia mediocridad. El aforismo viene a golpear la conciencia del lector con su nuevo punto de vista. Continuemos analizando ahora cómo se presenta la ironía en el siguiente texto:

(3) ¡Qué delicia ser tonto sin saberlo! (N. Guillén) 
Este aforismo pareciera ser la conclusión a la que llegó el autor después de una mirada atenta sobre el comportamiento humano. Por un lado, podemos leer en el texto que el ser humano puede sentir delicia y placidez por creerse "inteligente" o "listo" y, precisamente, ser tonto por ese engreimiento. Por otro lado, la cordura nos diría que, desde ningún punto de vista, ser tonto pudiera ser delicioso; pero aquí este texto dice que si fuéramos tontos sin percatarnos, sin enterarnos, tendríamos una vida inconscientemente feliz y deliciosa; es entonces la inconsciencia la que nos proporcionaría una maravillosa vida inocente e ingenua, en apariencia sin culpas, sin mortificaciones, sin confusiones, sin angustia.

Veamos ahora algunos elementos que tienen que ver con la parodia. Puede decirse que un texto es paródico cuando en su construcción intervienen elementos de otros discursos, orales o escritos. En este sentido, la parodia es un hecho de intertextualidad, puesto que en el tejido de la parodia participan voces de otros textos tomados de la cultura. Es sabido que en cualquier discurso siempre están presentes las voces de otros, pero en la parodia la incorporación de esas voces no tiene la única intención de hacer un homenaje al texto original, sino de convertirlo en objeto de risa y de juego, e incluso pretende desenmascarar la falsedad, la mendacidad del discurso ajeno, como dice Bajtín (1982, 248-293).

En el discurso aforístico es frecuente encontrar parodias de distintos tipos de discurso; los más comunes son el bíblico, el de refranes, sentencias y proverbios, el discurso de la argumentación lógica, etc. Quizá es importante considerar que estos tipos de discurso se han caracterizado por expresar las grandes verdades religiosas, populares o científicas. Veamos los siguientes casos:

(4) Dios mio, en vuestras manos entrego mi cuerpo. (M. Yourcenar)

(5) Dichosos los que saben que el sufrimiento no es una corona de gloria. (J. L. Borges)

Los dos aforismos anteriores están conformados a partir del discurso bíblico, sin embargo, ambos lo citan para decir justamente lo contrario: en el primero, el juego se logra a partir de la sustitución de la palabra espíritu por cuerpo, y con ello se da entrada a una visión nueva y distinta de la que ha mantenido el cristianismo, es decir, el espíritu pierde en el aforismo el prestigio que ha tenido durante mucho tiempo y llama la atención hacia la importancia del cuerpo, lo re-valora y lo coloca en el mismo nivel jerárquico que el espíritu o el alma tenían en el texto bíblico. En el aforismo (5), se niega que el sufrimiento sea un valor; formalmente, es casi una cita del texto bíblico, pero, otra vez, utiliza esta voz para decir lo contrario, es decir, negar que el sufrimiento sea un valor y negar asimismo la idea de que el sufrimiento sea garantía de grandeza y de gloria; en este aforismo se exalta a quienes se han percatado de que la gran promesa cristiana es una enorme mentira.

Tres ejemplos de aforismos que se estructuran a partir de refranes, proverbios o máximas son:

(6) ¿No es mejor nunca que tarde? (P. Neruda)

(7) Si a uno le dan palos de ciego, la única respuesta eficaz es dar palos de vidente. (M. Benedetti)

(8) Se ahoga más gente en los vasos que en los rios. (G. Lichtenberg) 
En los tres se contradice o se hace burla del saber popular; se parodia de manera irónica porque el juego introduce una inversión que le da un nuevo sentido a los textos, los revitaliza, al proponer una idea distinta de la comúnmente aceptada y con ello se propone una mirada que el saber popular no ha considerado; todo el mundo suele repetir los refranes de manera mecánica, y la parodia rompe este automatismo de la palabra hecha, heredada y congelada. Además, agregan un humor saludable, que quizá no llega al sarcasmo; parecen producto de un solo e inocente juego, donde brilla el ingenio, la nueva propuesta de visión de las cosas.

El discurso de la lógica es quizá uno de los más parodiados por el aforismo; al hacerlo, utiliza argumentaciones tan aparentemente elaboradas o sustentadas como las que encontramos en los textos filosóficos; veamos un caso:

(9) Toda vida es la historia de un hundimiento. Si las biografias son tan cautivadoras es porque los héroes, al igual que los cobardes, se fatigan innovando en el arte de besar el suelo. (E.M. Ciorán)

Este aforismo inicia con una afirmación categórica; el empleo de la frase cuantificada toda vida contribuye a crear el efecto de una generalización que, posteriormente, va a ser sostenida mediante "supuestos" argumentos construidos formalmente de acuerdo con el discurso de la lógica y pretenden erigirse en argumentos que prueban una verdad; sin embargo, esa verdad no es real, no es verosímil, es casi un absurdo, en la medida en que nadie esperaría que un tema de esa naturaleza fuera estudiado por la lógica o desde un punto de vista estrictamente racional. En el proceso argumentativo que da sustento a la generalización, las nociones de "biografia" y de "héroe" que aluden a la grandeza que puede alcanzar el ser humano, se someten a burla; el héroe es puesto en el nivel del cobarde y, además, se le asocia con acciones no grandiosas, sino mezquinas, denigrantes, humillantes, a partir de las cuales el héroe obtiene la fama y la gloria.

Enseguida examinaremos algunos de los recursos en los que se apoyan tanto la ironía como la parodia:

- El empleo de la forma de la definición.

- Cuantificadores para expresar generalizaciones que dan la impresión de referirse a una gran verdad.

- Expresiones que aluden a un deber ser, en un contexto irónico.

- Expresiones inacabadas, sugerentes, como si estuvieran fuera de contexto-sin estarlo-y que más bien plantean dudas y siembran la inquietud.

- Exclamaciones o preguntas ingeniosas, aparentemente inocentes.

Veamos primero cómo se parodia la forma de la definición. En términos generales, definir es manifestar el significado o la esencia de algo, por ello suelen asociarse dos sintagmas nominales referenciales unidos con el verbo copulativo ser. En el discurso aforistico, esta asociación se hace de manera lúdica o irónica, puesto que lo que se dice del objeto es inesperado, desde el punto de vista lógico o del sentido común; por ejemplo:

(10) La simpatia es una pésima limosna. (G. Lichtenberg)

(11) Desembarazarse de la vida es privarse de la satisfacción de reirse de ella. (E. M.Ciorán) 
Los dos ejemplos anteriores emplean el verbo ser y lo que se dice del sujeto es sorpresivo, inusual, extraño, dado que no responde a las expectativas del lector, sino que apela a otros marcos de referencia, en los que la ironia es indispensable. Por ejemplo, en relación con el aforismo de Lichtenberg, podemos decir que, en nuestra cultura, la simpatía es un valor que remite a aceptación social; en el texto, este valor es subvertido y degradado al atribuírsele cualidades desdeñables. Definir la "simpatia" de esta manera es considerarla como una concesión fútil, que denigra, como lo puede hacer la peor limosna; esto, por supuesto, no es ni verdadero ni falso, sino que la idea ataca el sistema de valores que constituyen la base sobre la que se erige el comportamiento humano convencional, el cual casi siempre enmascara y oculta la mezquindad, el egoísmo, la hipocresía y, en general, todas aquellas debilidades propias del ser humano. Villoro $(1989,68-80)$ ha analizado y comentado esta actitud crítica que muestra Lichtenberg en sus aforismos.

Es evidente la intención irónica en el aforismo (11). ¿Dónde se ha oído que el suicidio no valga la pena porque impediría reírse de la vida? En este juego, todo lo serio que tiene vivir y suicidarse se derrumba y en su lugar la risa se impone. En este aforismo subyace una alusión a que la vida sólo tiene sentido y es soportable si podemos mofarnos de ella; es decir, el reírse de la vida es lo que verdaderamente tiene sentido y, a su vez, le daría un sentido a la vida misma. Esto último llega incluso a cuestionar la idea de que el suicidio es "la expresión suprema de la libertad." ¿Qué podría estar detrás de este aforismo? ¿Por qué exaltar al nivel de un valor el reírse de la vida? Probablemente, las ilusiones, sueños y deseos se frustran o se vuelven vanos y sin sentido ante las limitaciones y la fragilidad del ser humano, asediado por la vejez, la enfermedad, el desamor y la muerte. Sin duda, todo esto se ha asumido de manera solemne y hasta trágica en nuestra sociedad, pero en el aforismo se sugiere que todo ello puede ser o debe ser objeto de risa.

No sólo encontramos la definición en su forma canónica, también la encontramos:

- Con el empleo de verbos como consistir, llamarse, parecer, ejemplos:

(12) El tedio consiste en la ausencia de una mitología. (F. Pessoa)

(13) Fascinar quiere decir hechizar, magnetizar, encantar; asi mismo: engañar. (O. Paz)

- Con la supresión del verbo de enlace y en su lugar colocando un signo de puntuación:

(14) Estómago: origen de las religiones, brújula del mundo. (L. Cardoza y Aragón)

(15) La solemnidad: un recurso del cuerpo para ocultar las fallas de la inteligencia. (A. Monterroso)

- Con el verbo ser combinado con negación o preguntas:

(16) Retardar el placer, ¿no es la astucia más elemental del deseo? (D. de Rougemont)

(17) ¿No será la vida un pez preparado para ser pájaro? (P. Neruda)

Otros de los recursos es el empleo de expresiones cuantificadas, de términos de polaridad o de expresiones como "hay algo...," "existe...," "hay quienes..." Todas estas 
formas pretenden generalizar y, con ello, ayudan a sustentar lo que en el aforismo se concibe como una verdad absoluta; por ejemplo:

(18) La mayoria de los hombres es más pernosa que ambiciosa: de ahi el éxito de los imbéciles. (A. Maurois)

(19) Hay algo más triste que envejecer, y es permanecer niño. (C. Pavese)

(20) No hay nada que pueda llenar tanto a una persona como los celos. (M. Kundera)

En los cuatro aforismos se hace una generalización; es interesante tener presente que la ciencia suele emplear un lenguaje de este tipo, puesto que le corresponde formular leyes o principios generales que explican distintos tipos de fenómenos. La actitud generalizadora de los aforismos es sin duda una parodia del discurso científico, con el fin de poner en evidencia cosas que no suelen ser vistas o a las que no se les dedica especial atención; de nuevo estamos ante la enunciación de verdades absolutas que no necesariamente son verdades verificables, algunas de ellas, más bien, mueven a la risa por inesperadas, por absurdas o ridículas u obvias; por supuesto, también invitan a la reflexión porque expresan una manera distinta de mirar y de evaluar el mundo. Los cuatro aforismos tienen que ver con asuntos que a toda persona interesa en la medida en que todos queremos encontrar una explicación de qué somos y por qué actuamos como lo hacemos; algunos de ellos abordan asuntos de orden cotidiano pero la fuerza y el énfasis que adquieren es sólo un truco para voltear las cosas, darles otro giro y modificar la apreciación de la vida.

Otro recurso relacionado con la generación del efecto irónico o paródico es la formulación del aforismo mediante una frase aparentemente inacabada, una exclamación o una pregunta que parece ser producto de un razonamiento que no se explicita en el texto, sino que únicamente se sugiere, se evoca; algunos ejemplos serían:

(21) La esperanza, esa prostituta. (J.A.B.D'Aurevilly)

(22) ¡Cuántos amargos tragos es la vida! (M. Hernández)

(23) ¿Para qué sime la sangre si podemos tener whisky en las venas? (J. Dos Passos)

Este recurso es quizá uno de los más interesantes, pues logra decir mucho sólo insinuando; con unas cuantas palabras los aforismos promueven la reflexión profunda; en (21) la esperanza-sin la cual el ser humano se hunde--es vista como una coartada para poder vivir y se define con dos palabras: "esa prostituta." Nos parece evidente el contraste que se muestra en este aforismo: relacionar la esperanza con una prostituta suena contradictorio; en nuestra cultura, la idea de "esperanza" está cargada de connotaciones positivas, alude a todo lo bueno que puede deparar el porvenir; la esperanza es promesa y toda promesa es dulce, augura futuro, bienestar y vida. En contraste, la prostitución es algo que ensucia, que amarga, que engaña. El aforismo no hace otra cosa, una vez más, que poner en evidencia lo falso, inocuo y sin sentido de nuestras esperanzas; aquí, la esperanza es algo despreciable y amargo pues vivir con esperanza equivale a vivir engañados.

El aforismo (22) es una exclamación de sólo unas cuantas palabras; la expresión es incompleta y adquiere sentido por lo que calla, por lo que no dice. El lector se ve obligado a llenar ese espacio de indeterminación semántica, pero no puede hacerlo con 
cualquier cosa porque el aforismo ya sugiere el camino, lo evoca. En (23) tenemos un recurso similar, aunque intervienen en él otros elementos que no podemos desarrollar aquí; la pregunta se hace no para obtener respuesta sino para hacer pensar, para hacer una búsqueda de otros sentidos posibles; la pregunta en sí es casi absurda, pero la trascendencia se advierte en la actitud lúdica y paródica del enunciador: entre otras cosas, juguemos a tener alcohol, a tener euforia en las venas.

Otro procedimiento frecuente en la construcción del aforismo es el empleo de expresiones que tienen un tono de obligatoriedad, es decir, hacen alusión a lo que debe ser o a lo que debe hacerse, pero la manera como lo expresan es asumiendo que se tiene la verdad y que es la única. En realidad, se trata de un juego, porque son verdades "desobedientes" pero que mueven a la reflexión, a la crítica y al jolgorio. Veamos los siguientes:

(24) Hay que levantar hombres a las estatuas. (M. Hernández)

(25) En arte, un mal adulterio es mejor que un buen matrimonio. (J. Torres Bodet)

(26) Lo que hay que tener es hambre. (J. Cuesta)

Además de los recursos mencionados anteriormente, es posible advertir en muchos aforismos el humor está presente como una forma para aligerar lo denso, jugar con lo sublime, trivializar lo grave o hacer una fiesta con la inteligencia y el lenguaje (Bioy Casares 1999, 77-82). Además, en la construcción de muchos textos aforísticos intervienen la paradoja, conclusiones sorpresivas o inesperadas y, por supuesto, la metáfora.

Hemos visto que el aforismo constituye un discurso construido dinámicamente por la ironía y la parodia; se trata de un discurso cuya eficacia se basa en frustrar las expectativas del lector, al comunicarle algo imprevisto, sorpresivo y novedoso, opuesto a lo esperado y así generar nuevos sentidos y crear un nuevo horizonte de conocimiento y de sensibilidad.

Para terminar, quisiéramos decir que el aforismo cumple una función hasta cierto punto liberadora dado que, fundamentalmente, mueve a la risa, a la risa irónica. Pero además, muestra al ser humano en todas sus imperfecciones, en sus pequeñeces, aunque lo hace sin trasmitir amargura, sino más bien, lo hace creando una visión distinta de la realidad, ofreciendo una nueva verdad placentera y gozosa, finalmente liberadora, puesto que representa esa fuerza saludable que emana del conocimiento.

\section{Obras citadas}

Bajtín, Mijail. 1982. Estética de la creación verbal. Trad. Tatiana Bubnova. México: Siglo XXI.

Bartolomé, Manuel y María Vidal C. 2000. "Prólogo." En Escritos y dichos sobre el libro. Barcelona: Edhasa.

Bioy C., Adolfo. 1999. "El humor en la literatura y en la vida." De las cosas maravillosas. Buenos Aires: Temas.

Booth, Wayne. 1986. Retórica de la ironia. Trad. Jesús Fernández Zulaica y Aurelio Martínez B. Madrid: Taurus.

Carreter, F. Lázaro. 1981. "La lengua de los refranes. ¿Espontaneidad o artificio?” Estudios de lingüistica. Barcelona: Crítica-Grijalbo. 219-232. 
Cheymol, Marc. 1987. Antologia. Máximas francesas. Trad. Julieta Arteaga. México: Offset.

El haikú japonés. 1966. México: Oasis.

Gurméndez, Carlos. 1990. "La ironía." El pais, 20 de enero (12).

Hutcheon, Linda. 1992. "Ironía, sátira, parodia. Una aproximación pragmática a la ironía." De la ironia a lo grotesco (en algunos textos literarios hispanoamericanos). México: UAM-I. 173-193.

Mizzau, Marina. 1984. L'ironia. La contraddizione consentita. Milán: Feltrinelli.

Munguía Z., Irma y Gilda Rocha. 1992. Aforismos. Una selección libre. México: UPN.

Reyes, Alfonso. 1976. "De los proverbios y sentencias vulgares." Obras completas, I. México: FCE.

Riffaterre, Michael. 1976. Ensayos de estilistica general. Trad. Pere Gimferrer. Barcelona: Seix Barral.

Sperber, Dan y Deirdre Wilson. 1978. "Les ironies comme mentions," Poetique, 36, 399-412.

Villoro, Juan. 1989. "La voz en el desierto." Aforismos. Georg Christoph Lichtengberg. México: FCE.

\section{Textos aforísticos citados}

(1) Cioran, E. M. 1986. De lágrimas y de santos. Trad. Rafael Panizo. Barcelona Tusquets.

(2) Rosenberg, Leonardo. 1986. Sentencias y disidencias. México: S/e.

(3) Guillén, Nicolás. 1972. Antología mayor. México: Juan Pablos.

(4) Yourcenar, Marguerite. 1995. Fuegos. Trad. Emma Calatayud. México: Alfaguara.

(5) Borges, Jorge Luis. 1989. Obra poética. Buenos Aires: Emecé.

(6) Neruda, Pablo. 1977. Libro de las preguntas. México: Seix Barral.

(7) Benedetti, Mario. 1981. Cotidianas. México: S. XXI.

(8) Lichtenberg, Georg Christoph. 1989. Aforismos. Trad. Juan Villoro. México: FCE.

(9) Cioran, E. M. 1988. Ese maldito yo. Trad. Rafael Panizo. Barcelona: Tusquets.

(10) Lichtenberg, Georg Christoph. (1989)

(11) Cioran, E. M. (1988)

(12) Pessoa, Fernando. 1996. Máscaras y paradojas. Ed. Perfecto E. Cuadrado. Barcelona: Edhasa.

(13) Paz, Octavio. Los hijos del limo. 1985. México: Seix Barral.

(14) Cardoza y Aragón, Luis. 1977. Poesías completas y algunas prosas. México: FCE.

(15) Monterroso, Augusto. 1996. Cuentos, fábulas y lo demás es silencio. México: Alfaguara.

(16) Rougemont, Denis de. 1993. El amor y occidente. Trad. Antoni Vicens. Barcelona: Kairós.

(17) Neruda, Pablo (1977)

(18) Maurois, André. 1981. "La conversación." Trad. José Gorostiza. Revistas literarias mexicanas modernas. Contemporáneos VI (Enero/marzo de 1930) y VII (Abriljunio de 1930). (Ed. Facs.) México: FCE. 
(19) Pavese, Cesare. 1970. El oficio de vivir. Trad. Luis Justo. Buenos Aires: Siglo Veinte.

(20) Kundera, Milán. 1988. La insoportable levedad del ser. Trad. Fernando de Valenzuela. México: Tusquets.

(21) D'Aurevilly, J. A. Barbey. 1990. Cit. en Nuevo diccionario antológico de pensamientos y aforismos. Gregorio Doval (recop. y selec.) Madrid: Edaf.

(22) Hernández, Miguel. 1973. El rayo que no cesa. Buenos Aires: Losada.

(23) Dos Passos, John. 1981. Manhatan Transfer. Trad. José Robles. Barcelona: Bruguera.

(24) Hernández, Miguel (1973)

(25) Torres Bodet, Jaime. 1981. "Máximas y mínimas de la costumbre." Revistas literarias mexicanas modernas. Contemporáneos. II. (Sept./dic. 1928) (Ed. Facs.) México: FCE.

(26) Cuesta, Jorge. 1994. Obras, I. México: del Equilibrista. 